\title{
DIVERSAS ABORDAGENS CONCEITUAIS SOBRE O TRABALHO EM REDE
}

\author{
Alexandra Cronemberger Rufino \\ Universidade Federal do Piauí - UFPI - Brasil \\ Washington Luís de Sousa Bonfim \\ Universidade Federal do Piauí - UFPI - Brasil
}

\section{Resumo}

Diversas abordagens conceituais sobre o trabalho em rede. Rede é uma forma de interação social e organizacional em que se formam laços entre indivíduos e/ou instituições para o alcance de um objetivo comum. Este artigo apresenta as várias abordagens conceituais possíveis para o termo rede, as quais dependem da área de conhecimento e do contexto em que as redes estejam inseridas. Além disso, demonstra que elas assumem diversas tipologias, dependendo dos atores envolvidos em sua formação e dos laços que os unem. Para tanto, realizou-se uma revisão bibliográfica que permitiu abarcar todos os universos propostos. Por fim, foram demonstradas as conclusões, em que ficou evidente a importância e as facilidades da utilização das redes atualmente, mas também, que esta forma de associação não está imune às críticas nem livre de tensões.

Palavras-chave: Rede. Associação. Tensão.

\section{Introdução}

O conceito de rede não é novo, ele já foi adotado como forma de organização social e na gestão de serviços sociais em outras épocas. Contudo, sua concepção atual se diferencia do modelo anteriormente utilizado, pois a sociedade contemporânea está estruturada com base no paradigma tecnológico, o qual permite que se estabeleçam conexões entre o local e o global em tempo real e de maneira dinâmica, fazendo com que essa antiga forma de organização social ganhe novas capacidades.

As redes resultam da interação entre indivíduos e organismos que se ligam entre si pelo compartilhamento de intencionalidades e valores na busca de um objetivo comum. Estes são os requisitos básicos para a formação de uma rede, contudo, ela pode apresentar conceitos diferenciados, dependendo do campo em que se encontre inserida.

\footnotetext{
* Doutor em Ciência Política e Sociologia pelo IUPERJ.

** Mestranda do Programa de Pós Graduação em Políticas Públicas pela Universidade Federal do Piauí - UFPI. E-mail: alexandrarufino@hotmail.com.
} 
Este artigo pretende apresentar diferentes abordagens conceituais sobre as redes, bem como sua tipologia, para demonstrar que, respeitadas as características de cada área, a adoção do trabalho com redes pode apresentar vantagens e desafios próprios do campo de ação.

Para alcançar o objetivo proposto, estruturou-se o artigo em três partes. Inicialmente, apresentam-se os fatores propícios à formação do trabalho em rede na sociedade atual. Além disso, demonstram-se as características comuns às redes na contemporaneidade diferenciandoas da maneira que se estruturavam as antigas redes.

Em seguida, serão descritos os conceitos de rede no campo da sociologia, administração pública, políticas públicas, políticas sociais e controle. Pretende-se com isso esclarecer as diferentes razões e os objetivos almejados quando da formação das redes pelos indivíduos e organizações.

Por fim, trata-se da tipologia de redes. Estas diversas classificações apresentadas pela literatura dependem dos atores envolvidos, dos laços que os unem e das necessidades que pretendem alcançar com a união de esforços e ajudam a compreender que tipo de rede é mais adequado a cada situação.

A metodologia utilizada foi a pesquisa bibliográfica, porque ela permitiu visitar as diferentes áreas de conhecimento e absorver dos autores escolhidos, os argumentos necessários para o alcance dos objetivos propostos.

\section{Fatores propícios à formação das redes}

No senso comum, o termo rede sugere a articulação indivíduos e/ou instituições que se unem, por terem afinidades para juntar esforços em função de possuírem objetivos comuns.

Gonçalves e Guará (2001) ensinam que, nas relações humanas, o termo rede é, comumente, considerado como representação organizacional, relações de apoio mútuo, articuladas através das relações de parentesco, de amizade ou de vizinhança, desta forma, a base de construção das redes é a confiança entre os participantes.

Outro significado comum para o termo rede é de movimento, de fluxo de informações, de conexão entre pessoas. A grande vantagem das redes é de aproximar as pessoas que estão em localidades distantes. Neste contexto, as redes sociais, especialmente, as tecnológicas são consideradas como a forma de associação por excelência.

No entanto, a concepção de rede é bem mais antiga que isso. Esta palavra vem do latim "retis" e significa entrelaçamento de fios com aberturas regulares que formam uma espécie de 
tecido. Foi a partir desse conceito que a palavra rede foi ganhando o significado de entrelaçamento, malha e estrutura reticulada, passando a ser empregada em diferentes situações.

Segundo Santos (2006), o mundo atual se caracteriza pela exigência de fluidez para a circulação de ideias, de mensagens, de produtos ou de dinheiro, interessando aos atores hegemônicos. Essa fluidez contemporânea baseia-se nas redes técnicas, que são um dos suportes da competitividade, por esta razão a constante busca por mais fluidez, provoca o desenvolvimento de novas técnicas ainda mais eficazes. "A fluidez é, ao mesmo tempo, uma causa, uma condição e um resultado" (SANTOS, 2006, p. 185).

No mesmo sentido, Castells (2005) afirma que o processo de transformação multidimensional a que está sujeita a estrutura da sociedade contemporânea está associado ao desenvolvimento de novas tecnologias de comunicação e informação, iniciado nos anos de 1960 e difundido por todo o mundo nas décadas posteriores. Esse novo paradigma tecnológico propiciou aos homens uma maneira diferente de se organizar.

Foi diante da complexidade do mundo atual e das tecnologias disponíveis, que as redes ganharam um novo sentido nos vínculos interorganizacionais. No modelo anterior de organização das redes, prevalecia a centralização, a hierarquização e a subordinação.

Atualmente, as características presentes no modelo de rede são: a circulação, a articulação, a participação; a cooperação; a horizontalidade e a complementaridade. Isso porque, elas acompanham os avanços tecnológicos, conectando o local com o global, acompanhando o comportamento próprio da sociedade contemporânea globalizada (CARVALHO, 2003).

Cardoso e Castells (2005) afirmam que a sociedade em rede é a nossa sociedade, a sociedade constituída por indivíduos, empresas e Estado operando num campo local, nacional e internacional.

Este, portanto, é o cenário propicio para a formação do trabalho em rede, o qual pode adotar diferentes definições e tipos, dependendo da abordagem e do ambiente em que é utilizado. Esta diversidade de conceitos e tipologias será explorada a seguir.

\section{Abordagens dos conceitos de rede}

Acioli (2007) adverte que tratar sobre o fenômeno de redes significa trabalhar com concepções variadas que misturam ideias ligadas ao senso comum, à experiência cotidiana do mundo globalizado ou a determinado referencial teórico-conceitual. Portanto, ela advoga sobre 
a importância de se estabelecer a desnaturalização da noção de rede, situando-a de maneira correta nas várias abordagens em que ela vem sendo empreendida.

Esta preocupação é válida devido ao fato de que as redes são utilizadas por diversas áreas do conhecimento para explicar, cada uma a seu modo, as relações entre indivíduos e/ou organizações ao longo do tempo.

Por esta razão, apresentam-se a seguir as concepções de rede em algumas abordagens teóricas para demonstrar a funcionalidade e a importância das redes para cada uma delas.

\subsection{Sociologia}

A sociologia é uma ciência que tem como objeto de estudo a sociedade. Os fenômenos estudados por esta área do conhecimento são: a organização social (diferentes formas de constituição das sociedades); os processos que interligam os indivíduos em grupos, instituições e associações e os aspectos culturais apresentados por cada sociedade. Diante disso, o estudo de rede é bastante pertinente a este campo do conhecimento.

Para as ciências sociais, o termo rede traduz o conjunto de relações sociais entre os atores sociais e também entre um conjunto de atores e designa os movimentos pouco institucionalizados, reunindo indivíduos ou grupos numa associação cujos limites são variáveis e sujeitos a reinterpretações (ACIOLI, 2007).

Historicamente, o conceito de rede surgiu na antropologia social em sentido metafórico, quanto Claude Lévi-Strauss apresentou sua análise etnográfica das estruturas elementares de parentesco. Portugal (2007) afirma que, nesta abordagem, não havia identificação de características morfológicas, necessárias para a descrição de situações específicas, nem eram estabelecidas as relações entre as redes e o comportamento dos indivíduos que as constituíam.

Com o tempo, o termo foi ganhando contornos analíticos, quando foi transformado em uma ferramenta de análise dos relacionamentos entre as pessoas, seus elos e entre as organizações do contexto em que estão inseridos (ACIOLI, 2007).

Sobre este sentido, Portugal (2007) apresenta duas correntes de pensamento. A primeira ligada à antropologia social britânica, que se preocupa com a análise situacional de grupos restritos, ocupando-se da normatividade dos sistemas culturais. A segunda vinculada à corrente americana, que se preocupa com a análise quantitativa para descrever modelos de relação, a qual se dividiu em duas linhas, uma formalista (concentrada na morfologia das redes e no seu impacto sobre os comportamentos) e a outra estruturalista (que define a relação como a unidade básica da estrutura social). 
Foi com a abordagem estruturalista que o conceito de rede passou de uma visão minimalista de metáfora, útil apenas para complementar uma análise, para uma posição maximalista traduzida no texto de Wellman e Berkowitz apud Portugual (2007, p. 07) da seguinte forma:

\begin{abstract}
As estruturas sociais podem ser representadas como redes - como conjuntos de nós (ou membros do sistema social) e conjuntos de laços que representam as suas interconexões. Esta é uma ideia maravilhosamente libertadora. Dirige o olhar dos analistas para as relações sociais e liberta-os de pensarem os sistemas sociais como colecções de indivíduos, díades, grupos restritos ou simples categorias. Usualmente, os estruturalistas têm associado «nós» com indivíduos, mas eles podem igualmente representar grupos, corporações, agregados domésticos, ou outras colectividades. Os «laços» são usados para representar fluxos de recursos, relações simétricas de amizade, transferências ou relações estruturais entre «nós».
\end{abstract}

Acioli (2007) apresenta, então, uma terceira abordagem decorrente do conceito de rede para a sociologia que é a tecnológica. Segundo a autora, estão englobadas, neste sentido, as redes de informação, de conexão e as temáticas, que compõe o núcleo de tecnologias da informação, sendo o termo rede utilizado como definição do meio de acesso a informações, do contato com grupos ou pessoas através de rede de computadores.

Corroborando esta posição, Ribeiro (1999, p.2) afirma que:

Hoje, a noção de rede tende a ser deslocada da referência às relações sociais profundas em direção às mediações entre materialidade e ação social ou em direção aos elos, permitidos pelas novas tecnologias de informação e comunicação, entre esferas, níveis, instâncias e âmbitos da vida social.

A evolução do conceito de rede na sociologia mostra que o ponto de partida da análise relacional não deve ser os indivíduos isolados e, sim, as relações que os integram.

Portugal (2007) ensina que a análise das redes permite explicar o comportamento social baseado nos modelos de interação entre os atores sociais, pois ela baseia-se na premissa de que a rede tem uma realidade própria. Além disso, o exame das interações possibilita determinar o modo como os indivíduos são condicionados pelo tecido social em que se encontram, bem como, o modo como esses indivíduos se utilizam e modificam o tecido social consoante seus interesse.

\title{
3.2 Administração pública
}

A administração pública como elemento essencial das relações entre a sociedade e o Estado, não fica imune à revolução tecnológica e às consequências advindas da globalização.

Os Estados, então, procuram adequar-se a esta realidade buscando uma nova forma de organização para recuperar a legitimidade perante seus cidadãos e manter-se conectado a eles.

Castells (1998, p. 1) conceituou Estado-rede como sendo: 
[...] una arquitectura política adaptada a la gestión social y política de nuestro tiempo, expresión de formas políticas flexibles y de geometría variable, según las circunstancias, que se desarrollan en todo el mundo y que he caracterizado, en las páginas de este diario, como expresión de un nuevo tipo de Estado, el Estado red.

Minhoto e Martins (2001) explicam que a construção do conceito de Estado-rede elaborado por Castells se deu num cenário de reconstrução da capacidade de atuação do Estadonação, frente ao duplo desafio que se coloca na contemporaneidade:

[...] o de aumentar a sua operatividade, mediante a cooperação internacional, e o de recuperar a sua legitimidade, mediante a descentralização político-administrativa. A fim de obter operatividade, o Estado transfere poder a instâncias transnacionais. A fim de obter legitimidade, o Estado transfere poder a instâncias subnacionais (MINHOTO; MARTINS, 2001, p. 85).

Sobre a adequação do Estado ao novo paradigma tecnológico e ao novo modelo de gestão em escala local-global, Carvalho (2003) afirma que é quase compulsório e consensual um movimento externo de formação de blocos econômicos e um movimento interno de descentralização, flexibilização e fortalecimento da sociedade civil, para compor um novo pacto e condições de governabilidade.

Segundo Santos (2003), na concepção da reforma administrativa, a governabilidade depende da qualidade das instituições políticas, quanto à intermediação de interesses; da existência de mecanismos de responsabilização dos políticos e burocratas perante a sociedade e da qualidade do contrato social básico. Tais dimensões remetem à reforma política, essencial à reforma do Estado.

Foi diante dessa nova realidade que surgiu a necessidade de transformar o modelo de administração estatal de burocrático em gerencial, porque este último permite a execução dos serviços públicos de maneira eficiente, com a redução dos gastos estatais, evitando a sobreposição de despesas por órgãos estatais para o atendimento do mesmo objetivo. Ademais, o modelo gerencial busca a implementação de políticas públicas voltadas ao atendimento dos interesses da sociedade, estreitando os laços entre o Estado e a sociedade.

Ao explanar sobre a transformação da administração burocrática para a gerencial, Pereira (1996, p. 6) explica:

Aos poucos foram-se delineando os contornos da nova administração pública: (1) descentralização do ponto de vista político, transferindo recursos e atribuições para os níveis políticos regionais e locais; (2) descentralização administrativa, através da delegação de autoridade para os administradores públicos transformados em gerentes crescentemente autônomos; (3) organização com poucos níveis hierárquicos ao invés de piramidal; (4) pressuposto da confiança limitada e não da desconfiança total; (5) controle por resultados, a posteriori, ao invés do controle rígido, passo a passo, dos processos administrativos; e (6) administração voltada para o atendimento do cidadão ao invés de auto referida. 
O primeiro passo adotado foi a descentralização vertical das funções executivas do governo federal para os governos estaduais e municipais, que buscou a valorização do princípio republicano - direito do cidadão ao patrimônio público - e o aumento da governabilidade. A proximidade do cidadão trouxe à aplicação do recurso e à prestação de serviços públicos, maior grau de transparência e de eficiência, em função do aumento do controle social.

Neste sentido, o projeto da Rede de Governo, proposto no plano diretor da reforma do aparelho do Estado brasileiro, visava formar uma infra-estrutura física integrando as instituições do governo através de uma rede nacional, baseada em sistemas abertos e integrada por equipamentos de informática e telecomunicações.

Marques (2006) argumenta que, para se aproximar do cidadão, a administração pública foi forçada a transversalizar a sua organização, criando pontos únicos de contato e integrando formas de atendimento. Para a autora

[...] as redes na Administração pública permitem combinar a colaboração para um objetctivo comum com a conservação da autonomia relativa de cada um dos seus pontos nodais. Facilitam, por isso, a transição do modelo hierárquico do passado para um novo modelo não excessivamente centralizado, que está ainda a emergir (MARQUES, 2006, p. 3).

Junqueira (2000) adverte que a rede não é apenas a construção de uma realidade de vínculos, mas é também uma maneira de analisar e entender a realidade social. Ele afirma que "é por isso que da rede pode resultar um saber intersetorial, ou mesmo transetorial, que transcende as relações intersetoriais na construção de novos saberes, de novos paradigmas" (JUNQUEIRA, 2000, p. 6).

Para Carvalho (2003) a ação das redes instaura um novo valor ao Estado que é a cooperação, por meio dela, serviços, organizações governamentais e não-governamentais, comunidades locais, regionais, nacionais e mundiais se interconectam, ocorrem a mobilização de parcerias e as ações multi-setoriais; constrói-se participação, mobilizam-se vontades e implementam-se pactos de complementaridade.

A importância da adoção dessa nova forma de conceber e de estruturar o Estado é que ela trouxe grandes mudanças à formulação, implementação e execução das políticas públicas.

\subsection{Políticas públicas}

Para que as políticas públicas fossem pensadas na lógica das redes, surgiu a necessidade de redesenhar as instituições públicas e modificar a forma de prestação de serviços e ampliar a participação da sociedade na definição e fiscalização dessas políticas. 
Para entender essa necessidade, parte-se das constatações de Farah (2001) de que, até os anos 1980, prevaleceu no Brasil o paradigma de modelo centralizado da provisão estatal no que se refere à formação das políticas públicas, cujas características eram a centralização decisória e financeira na esfera federal, cabendo aos estados e municípios apenas o papel de executores dessas políticas; a fragmentação institucional, decorrente do desordenado crescimento do aparelho estatal, que provocou a sobreposição de agências na mesma área sem coordenação necessária à eficiência e efetividade das políticas e, no campo das políticas sociais, a organização em caráter setorial, que gerou a especialização e a autonomia das áreas, sem a articulação entre as ações realizadas, provocando, de um lado, a perda da potencialidade de efeitos positivos advindos da coordenação, e, de outro, o comprometimento de determinadas políticas, pela inexistência de serviços complementares.

Além disso, a autora constata a exclusão da sociedade civil do processo de formulação das políticas, da implementação dos programas e do controle da ação governamental (FARAH, 2001).

Estas características não se coadunam com o conceito de rede atualmente adotado, como fica claro a seguir.

Santos (2005) apresenta o conceito de rede de políticas públicas, entendendo que ela representa o processo em que a formulação das políticas envolve membros de uma ou mais comunidades políticas que estabelecem uma relação de interdependência. Para ele, não é aceitável a ideia de que o Estado é o único ator relevante no processo de formação das políticas, pois elas são o resultado da interação complexa entre agências estatais e organizações nãoestatais.

Neste sentido, Pfeifer (2009) argui que, no âmbito da literatura de administração pública, a definição de rede vincula-se à articulação entre diferentes atores, que convergem para o estabelecimento de uma agenda de trabalho conjunta que inclui desde a identificação de problemas até a implementação de programas, com o objetivo de alcançar a eficácia e eficiência das políticas públicas, a qual depende da participação de múltiplos atores.

Foi no contexto acima definido que floresceu a ideia do terceiro setor, componente essencial para a formação da rede de políticas públicas, em especial as sociais, no Brasil. No programa de reforma do Estado brasileiro dos anos 1990, ele aparece como uma ampliação do espaço público.

O processo de ampliação do setor público não-estatal ocorre a partir de duas origens: de um lado, a partir da sociedade, que cria continuamente entidades dessa natureza; de outro lado, a partir do Estado, que nos processos de reforma deste último quartel do século vinte, se engaja em processos de publicização de seus serviços sociais e científicos (PEREIRA, 1997, p. 28). 
Para Barbosa (2009), redes de políticas são arranjos interorganizacionais para a formulação e execução de políticas públicas, decorrente da estratégia da descentralização de recursos e de competências na sua execução. Sendo assim, vários atores são envolvidos nos processos de formação, implementação, controle e avaliação de políticas.

Os arranjos interorganizacionais também são abordados por Farah (2001, p. 22), quando a autora afirma que "tais arranjos apontam para a construção de redes institucionais que reúnem diversos atores, envolvendo articulações intersetoriais, intergovernamentais e entre Estado, mercado e sociedade civil".

Migueletto (2001) chama atenção para o novo tipo de rede surgido atualmente, o qual se caracteriza pela articulação de organizações e indivíduos por reconhecerem que não podem alcançar determinados objetivos de forma isolada, necessitando somar seus recursos na busca de um objetivo bem definido. Tais recursos são, por exemplo: informações, dinheiro, conhecimento, ou até mesmo, status, experiência e legitimidade.

As redes de políticas públicas concebidas pelo Estado têm essas características, pois são formadas pela parceria entre Estado e a sociedade civil, bem como entre instituições governamentais com o intuito de aumentar a governança e ampliar a abrangência dos programas disponibilizados à população.

\subsection{Políticas sociais}

No campo das políticas sociais, especialmente as vinculadas à assistência social, a discussão do trabalho em rede está ligada ao enfrentamento da questão social, aos debates sobre a democratização e à promoção da cidadania, conforme destaca Pfeifer (2009, p.6) que "a leitura das Redes de Políticas Sociais passa pela compreensão da questão social e a indispensável mediação das políticas para o acesso e a garantia de direitos sociais como resposta às suas expressões".

Junqueira (2000) afirma que as redes sociais são a integração de um conjunto de pessoas e organizações, que pretendem responder às demandas e necessidades da população, sempre respeitando o saber e a autonomia de cada membro. E, complementa que as redes são um meio para tornar mais eficaz a gestão das políticas sociais, pois otimizam a utilização dos recursos disponíveis.

Ao preservarem a identidade de cada membro e sua competência na gestão dos recursos, fazem com que essas organizações se integrem, tanto na concepção das ações intersetoriais quanto na sua execução, para garantir à população seus direitos sociais (JUNQUEIRA, 2000, p. 6). 
Para Neves (2009, p. 2), no campo da cidadania, as redes são "sistemas organizacionais capazes de reunir indivíduos e instituições, de forma democrática e participativa, em torno de objetivos ou realizações comuns".

Gonçalves e Guará (2010) conceituam a rede de proteção social como a articulação das intencionalidades de pessoas e de grupos humanos, que potencializam as iniciativas dos atores e dos agentes sociais para promover o desenvolvimento pessoal e social nas políticas sociais públicas.

Na concepção da intersetorialidade, a rede de política social é definida por Pereira e Teixeira (2013) como sendo uma nova gestão contrária à setorização e à especialização, propondo a integração e a articulação dos saberes e dos serviços, além da formação de redes e parcerias entre sujeitos coletivos no atendimento das demandas dos cidadãos.

O trabalho em rede na política social de assistência iniciou com a reformulação da Política Nacional de Assistência Social - PNAS, que criou o Sistema Único de Assistência Social - SUAS - responsável por promover a proteção social em dois eixos, o básico e o especial. Cada um dos eixos de trabalho deve contar com uma rede, que articule as unidades públicas e a sociedade civil.

Vitoriano (2011) informa que a adesão da ação em rede na PNAS é colocada como maneira de organização imperiosa no sentido de superar superposições e paralelismos de ações com o objetivo de multiplicar seus efeitos e chances de sucesso por meio da integração das ações e que as redes criadas pelo SUAS são do tipo socioassistenciais, formadas por organizações governamentais, organizações não-governamentais e segmentos empresariais, em que o Estado tem o papel de coordenador desse processo, devendo conferir unidade aos esforços.

Ademais, explica Vitoriano (2011) que estas redes se organizam com base na corresponsabilidade e complementaridade e que, segundo os documentos oficiais, a rede teria a possibilidade de alcançar a efetividade e completude das políticas frente à complexidade da situação de pobreza e desigualdades sociais existentes. Portanto, a construção da rede potencializaria o desempenho das políticas públicas, diante a escassez de recursos.

A esse respeito, Farah (2001) advoga que tal situação decorre do clima, ainda muito difundido no Brasil, de desconfiança com relação ao setor estatal e do questionamento da capacidade do Estado de alavancar o desenvolvimento e de executar a ação estatal em diversas políticas públicas, o que provocou uma onda minimalista para as práticas estatais. 
No mesmo sentido, Martins e Minhoto (2001) analisam as tensões presentes no trabalho em rede ponderando que as redes de solidariedade, presentes na área da assistência social, visam o alargamento da esfera pública, estratégia que possui um alto risco de privilegiar a privatização dos meios de gestão da questão social contemporânea.

Sendo a promoção da cidadania o principal objetivo das políticas sociais, sobretudo as de assistência social, é importante considerar as tensões existentes no trabalho em rede para que se respeite os princípios da universalidade e redistribuição estabelecidos na Constituição Federal de 1988.

Sobre o assunto, se pronunciam Pereira e Teixeira (2013) no sentido de que a articulação e complementação de políticas e saberes são necessárias para o tratamento integral dos problemas sociais, desta forma, a intersetorialidade deve ser compreendida como um arranjo complementar, capaz de responder às demandas que as políticas setoriais não são capazes, em virtude de suas limitações.

Entretanto, Vitoriano (2011) adverte que a ampla participação de entidades filantrópicas na prestação de serviços assistenciais, apresentado como "um 'novo' modelo participativo e democrático", ratifica a desresponsabilização do Estado.

\subsection{Controle}

Em detrimento da forma de articulação adotada pelo Estado para executar as políticas públicas, se diretamente ou através de uma rede interorganizacional, é indispensável que haja a fiscalização dos recursos públicos despendidos e os órgãos de controle são fundamentais para esta tarefa.

Por este motivo, o Plano Diretor da Reforma do Estado de 1995 criou vários recursos tecnológicos que permitiam o armazenamento de informações governamentais, como forma de estruturar os mecanismos de controle e de formar a base das informações gerenciais necessárias ao controle da máquina estatal.

Pereira (2002, p. 9) descreve os projetos que objetivaram aumentar a transparência do Estado:

1. Projeto Cidadão. Esse projeto tem como propósito aperfeiçoar as relações entre a Administração Pública e o cidadão, simplificando obrigações de natureza burocrática, implementando dispositivos de reclamações e sugestões do cidadão sobre a qualidade dos serviços públicos, minimizando o tempo de espera do cidadão para ser atendido, entre outras medidas.

2. Rede de Governo. Visa esse projeto montar uma moderna rede de comunicação de dados no setor público, de forma a poder repassar à sociedade em geral e aos próprios 
órgãos do governo, a maior quantidade possível de informação, contribuindo para melhor transparência e maior eficiência na conduta dos negócios de Estado.

Esse foi o marco inicial para a formação das redes de controle, pois os projetos idealizados possibilitam, de um lado, a articulação entre Estado e sociedade civil, e, de outro, a articulação entre os órgãos estatais, aumentando a troca de informações e a transparência dos negócios públicos.

Nesta senda, o Tribunal de Contas da União (TCU) criou em 2009 o Programa Diálogo Público, que busca, entre outros objetivos, promover a integração e o intercâmbio de conhecimento em assuntos de interesse controle externo; estimular o controle social e desenvolver competências para a boa gestão dos recursos públicos (BARBOSA, 2009).

O programa é executado em duas linhas de atuação, a capacitação de gestores públicos e a implantação da Rede de Controle da Gestão Pública, a qual foi implementada nas esferas federal e estaduais (BARBOSA, 2009).

No documento Rede de Controle: construindo parcerias para o controle efetivo da gestão pública, o TCU (2010) apresenta o contexto e as justificativas utilizadas para a formação da rede.

De acordo com o documento, as instituições que exercem o controle dos gastos públicos devem encontrar novas formas de atuação diante do ambiente complexo em que se materializam as políticas e os programas públicos. Essa nova estruturação decorre do ambiente da administração pública, caracterizado por recursos escassos e problemas complexos, pela atuação de múltiplos atores públicos e privados, locais e centrais, envolvidos no planejamento e execução de políticas públicas e pela crescente demanda por participação cidadã (TCU, 2010).

O novo arranjo interorganizacional é denominado pelo TCU (2010, p. 1) de organização em rede e explicado, nas palavras de Borzel, como sendo:

Redes são estruturas policêntricas, envolvendo múltiplas organizações ou partes delas, que se formam por relações estáveis, de natureza não hierárquica e interdependente, vinculando uma série de atores com um interesse comum em relação a uma política pública e que intercambiam recursos para concretizar esses interesses, reconhecendo que a cooperação é a melhor forma de atingir objetivos.

Finalmente, o TCU (2010, p. 1) conceitua a rede de controle como sendo um:

[...] núcleo de articulação subjacente a política pública de Controle, dentro do Estado, por se constituir em arranjo interorganizacional que pode estabelecer processos decisórios próprios, que devem estar em consonância com regramentos já estabelecidos no âmbito de cada Instituição partícipe. Pode, ainda, ser entendida como estratégia de descentralização da política de controle do Estado e como um novo espaço de interação na esfera pública, visando promover uma inteligência coletiva sobre a função de controle da gestão pública. 
Foi em virtude dessa realidade que houve a formalização da Rede de Controle na esfera federal, mediante assinatura de Protocolo de Intenções no dia 25/3/2009, em Brasília, em Fórum específico de criação da Rede de Controle da Gestão Pública.

O protocolo foi assinado pelas autoridades máximas de 17 instituições, dentre as quais se destacam, aqui, aquelas ligadas ao controle exercido pelo poder público em diversas áreas, que são: Advocacia Geral da União; Câmara dos Deputados; Conselho da Justiça Federal; Conselho Nacional de Justiça; Controladoria-Geral da União; Ministério do Planejamento, Orçamento e Gestão; Ministério Público Federal; Senado Federal; Tribunal de Contas da União e Tribunal Superior Eleitoral.

Percebe-se pelo exposto, que a fragmentação institucional, decorrente do desordenado crescimento do aparelho estatal, já mencionada quando da discussão sobre rede no âmbito das políticas públicas, está presente também na função de controle exercido pelo Estado.

Assim, com a formação da Rede de Controle, primeiro na esfera federal e, depois, nas esferas estaduais, busca-se promover eficiência e efetividade das políticas de controle, bem como a articulação entre as ações realizadas, evitando a sobreposição de esforços para o alcance de objetivos comuns.

\section{Tipologias}

Franco (2011), criador da Escola de Redes, destaca que a organização de uma sociedade em rede sempre existiu, desde que existem os seres humanos. Portanto, as redes sociais não surgiram com as novas tecnologias de informação e comunicação.

Para ele, a grande novidade do tempo em que vivemos não é o surgimento de uma sociedade em rede, mas a generalização do entendimento de que sociedade é igual à rede social.

Corroborando esta afirmação, apresenta-se a seguir alguns tipos de associação social e organizacional, que podem articular-se por meio da tecnologia, mas que não necessitam dela para existir.

A rede primária é um conjunto de indivíduos que estabelecem relações a partir de laços de afetividade, ela forma a trama de base da sociedade. Contudo, Guadalupe (2001, p. 1) adverte que embora a família seja apontada como o "núcleo duro" da rede primária, ela não é o seu quadrante exclusivo, deve-se sempre considerar os quadrantes das relações de amizade, vizinhança e companheirismo. "Esta gama de relações, que podem existir numa rede primária, constitui um importante recurso para o indivíduo no que toca ao apoio potencial que daí pode obter". 
Por rede secundária entende-se a agregação de pessoas que possuem a mesma função dentro de um marco institucionalizado. Nesta se incluem os grupos de apoio, as associações, os grupos de voluntários (PFEIFER, 2009).

As redes podem ser formais ou informais. Nas primeiras, as interações que as unem são espontâneas e as práticas não são formalizadas. Por outro lado, constituem-se como formais quando a organização é mais explicita, a ponto de serem traçados fronteiras e limites de atuação, denominação própria, gerando um novo nível de complexidade (MINHOTO; MARTINS, 2001).

Minhoto e Martins (2001) trazem, ainda, importante colaboração às tipologias de redes. Eles destacam que rede, no campo dos movimentos sociais, corresponde a articulação e interações entre grupos, organizações e indivíduos, com o objetivo de promover ações de reivindicação de formulação de políticas e projetos coletivos. No campo do Estado, as redes representam a articulação entre as agências governamentais e/ou entre estas e as redes sociais privadas para o enfrentamento dos problemas sociais e implementação de políticas públicas. Aqui, eles enquadram as redes institucionais, as redes secundárias formais, as redes sociogovernamentais e as redes locais de inserção.

Inojosa (apud MINHOTO; MARTINS, 2001) propõe a seguinte tipologia de rede: rede autônoma ou orgânica (constituída de centros autônomos, com objetivos específicos próprios, que se articulam em função de uma ideia abraçada coletivamente, preservando a identidade original de cada participante); rede tutelada (aquela em que os membros possuem autonomia relativa, pois se articulam sob a égide de uma organização que os mobiliza e modela o objetivo comum) e rede subordinada (modelo mais antigo, constituída de entes que são parte de uma organização, com interdependência de objetivos. Estas não se constituem pela vontade dos entes e, sim, pelo locus de controle).

Por fim, apresenta-se a categoria de rede estruturada no processo de comunicação de forma reticular, que apresenta como características a articulação de pontos que estão em lugares diferentes, sendo, por isso, policêntrica; não hierárquica; não linear; dinâmica; organizada em múltiplos níveis; com objetivos compartilhados, construídos coletivamente; fundada na desconcentração de poder e na circulação de informações (NEVES, 2009).

$\mathrm{O}$ fato de as redes apresentarem tantas tipologias, adotando diversos significados e modelos, demonstra sua dinamicidade e sua importância para as relações pessoais e organizacionais. 


\title{
5 Conclusão
}

Diante do exposto, é possível concluir que o trabalho em rede é essencial para a sociedade contemporânea, pois a rede possibilita o estreitamento dos laços entre as pessoas, aproxima as distâncias, propicia a união de esforços e a redução de custos para o alcance de objetivos comuns.

Ademais, as novas tecnologias disponíveis atualmente beneficiam a formação de redes entre os diversos agentes envolvidos em determinados processos. A conexão local/global tão necessária às redes horizontais, complementares e participativas, de hoje, é plenamente garantida pela fluidez presente nos sistemas de informação.

Porém, possivelmente, a maior importância das redes não seja nenhum dos fatores acima citados e, sim, o fato de que o termo rede se adéque às várias áreas do conhecimento, aceitando definições diferenciadas, a depender da abordagem em que esteja inserida, e, mesmo assim, conservando características essenciais a este modelo de organização.

Contudo, tais conclusões não significam que o trabalho em rede está imune a questionamentos. Como ficou claro na discussão sobre as políticas sociais, dependendo da forma que o trabalho em rede é articulado e das parcerias que são firmadas, as redes podem comprometer os objetivos almejados pelo público alvo de uma política social e distorcer a concepção de tal política.

\begin{abstract}
Several conceptual approaches on networking. Network is a way of social and organizational interaction where bonds among people or institutions are formed to reach a common goal. This article presents several possible conceptual approaches for the word "Netwok", which will depend on the field of knowledge and the context in which the networks are inserted. Besides, it shows that they accept several typologies, depending on the actors involved and the bonds that put them together. A bibliographic reference review was performed, which allowed all the possible scenarios to be included. Lastly, with the conclusions presented, the importance and facility of the use of networks nowadays, were evident, but also, that this way of association is not immune to criticism or free of tensions.
\end{abstract}

Keywords: Network. Association. Tension.

\section{Resumen}

Diversos abordajes conceptuales sobre el trabajo en red. Red es una forma de interacción social y organizacional en la cual se forman lazos entre individuos y/o instituciones para el alcance de un objetivo común. Este artículo presenta los varios abordajes conceptuales posibles para el término red, los cuales dependen del área de conocimiento y del contexto en que las redes estén inseridas. Además, demuestra que ellas asumen diversas tipologías, dependiendo de los actores envueltos en su formación y de los lazos que los unen. Para tanto, se realizó una revisión 
bibliográfica que permitió abarcar todos los universos propuestos. Por fin, fueron demostradas las conclusiones, en que quedó evidente la importancia y las facilidades de la utilización de las redes actualmente, pero también, que esta forma de asociación no está inmune a las críticas tampoco libre de tensiones.

Palabras clave: Red. Asociación. Tensión.

\section{REFERÊNCIAS}

ACIOLI. Sonia. Redes sociais e teoria social: revendo os fundamentos do conceito. Disponível em: $<$ http://www.uel.br/revistas/uel/index.php/informacao/article/viewFile/1784/1520>. Acesso em: 19 fev. 2013.

BARBOSA, Dione Mary de Cerqueira. Rede de controle da gestão pública: contribuições para a atuação do TCU. Disponível em:

<http://portal2.tcu.gov.br/portal/pls/portal/docs/2055742.PDF>. Acesso em: 12 dez. 2013.

BRASIL. Tribunal de Contas da União. Rede de Controle: construindo parcerias para o controle efetivo da gestão pública.

Disponível em: <file://C:/Users/alexandra.rufino/Downloads/1474907\%20(3).PDF>. Acesso em: 28 fev. 2014.

CARVALHO, Maria do Carmo Brant de. A ação em rede na implementação de políticas e programas sociais públicos. Disponível

em:<http://lasociedadcivil.org/docs/ciberteca/a_ao_em_rede_na_implementao.pdf $>$. Acesso em: 12 dez. 2013.

CASTELLS, Manoel; CARDOSO, Gustavo. Prefácio dos organizadores. In: A sociedade em rede:

do conhecimento à acção política. Disponível em:

$<$ http://www.cies.iscte.pt/destaques/documents/Sociedade_em_Rede_CC.pdf $>$. Acesso em: 13 fev. 2014.

CASTELLS, Manoel. Sociedade em rede: do conhecimento à política. In: A sociedade em rede:

do conhecimento à acção política. Disponível em:

$<$ http://www.cies.iscte.pt/destaques/documents/Sociedade_em_Rede_CC.pdf $>$. Acesso em: 13 fev. 2014.

El Estado red. Disponível em:

<http://www.amersur.org.ar/Integ/EstadoRedMC.htm>. Acesso em: 13 fev. 2014. 
FARAH, Marta Ferreira Santos. Parcerias, novos arranjos institucionais e políticas públicas no nível local de governo. Disponível em:

<http://bibliotecadigital.fgv.br/ojs/index.php/rap/article/view/6364/4949>. Acesso em 13 fev. 2014.

FRANCO, Augusto de. A rede. Disponível em:

<http://api.ning.com/files/ozuLmGL9D4b6eI8-jVK8cAV2Q2JE6tFHX6d45NffM6VwjX1YPgFOikbPuJiXdixcRKUy7m3mpFhWy8T5w0nJc1jIEhXXlpW/SrieFLUZZVolume1 AREDE.pdf>. Acesso em: 13 fev. 2014.

GONÇALVES, Antonio Sérgio; GUARÁ, Isa Maria F. Rosa. Rede de proteção social na comunidade. In: Redes de proteção social. Disponível em:

$<$ http://www.fazendohistoria.org.br/downloads/4_rede_de_protecao_social.pdf $>$. Acesso em: 12 fev. 2014.

GUADALUPE, Sônia. Intervenção em rede e doença mental. Disponível em: < http://www.cpihts.com/PDF03/Sonia\%20Guadalupe.pdf >. Acesso em: 13 fev. 2014.

JUNQUEIRA, Luciano. Intersetorialidade, transetorialidade e redessociais na saúde. Disponível em: <http://bibliotecadigital.fgv.br/ojs/index.php/rap/article/viewFile/6346/4931>. Acesso em: 12 fev. 2014.

MARQUES, Maria Manuel Leitão. Uma administração pública em rede. Disponível em:<http://www.apdsi.pt/uploads/news/id547/4.5_maria\%20leitao\%20marques_070626.pdf>. Acesso em: 13 fev. 2014.

MIGUELLETO, Danielle. Organizações em rede. Disponível em: $<$ http://bibliotecadigital.fgv.br/dspace/bitstream/handle/10438/3566/DanielleMiguelleto.pdf?s equence $=1>$. Acesso em: 20 fev. 2014.

MINHOTO, L.D.; MARTINS, C. E. As redes e o desenvolvimento social. Cadernos Fundap, n. 22, p. 81-101. 2001.

NEVES, Marília Nogueira. Rede de atendimento social: uma ação possível? Disponível em: $<$ http://catolicaonline.com.br/revistadacatolica2/artigosv1n1/13_Rede_de_atendimento.pdf $>$. Acesso em: 31 jan. 2014.

PEREIRA. Luiz Carlos Bresser. Da administração pública burocrática à gerencial. Disponível em: <http://blogs.al.ce.gov.br/unipace/files/2011/11/Bresser1.pdf >. Acesso em: 20 fev. 2014. 
A Reforma do estado dos anos 90: lógica e mecanismos de controle. Brasília: Ministério da Administração Federal e Reforma do Estado. 1997.

PEREIRA, Karine Yanne de Lima; TEIXEIRA, Solange Maria. Redes e intersetorialidade nas políticas sociais: reflexões sobre sua concepção na política de assistência social. Disponível em: <http://www.redalyc.org/articulo.oa?id=321527373009>. Acesso em: 20 fev. 2014.

PFEIFER , Mariana. Notas acerca das redes de políticas sociais. Disponível em: < http://www.observatoriodaeducacaosuperior.ufpr.br/artigos_1/ARTIGO-08.pdf $>$. Acesso em: 30 jan. 2014.

PORTUGUAL, Sílvia. Contributos para uma discussão do conceito de rede na teoria sociológica. Disponível em: <http://www.ces.uc.pt/publicacoes/oficina/ficheiros/271.pdf>. Acesso em: 20 fev. 2014.

RIBEIRO, Ana Clara Torres. A natureza do poder: técnica e ação social. Disponível em: <http://www.scielo.br/pdf/icse/v4n7/02.pdf>. Acesso em: 20 fev. 2014.

SANTOS, Hermílio. Perspectivas contemporâneas para a constituição de redes de políticas públicas. Disponível em: <http://www.redalyc.org/articulo.oa?id=74250104>. Acesso em: 30 jan. 2014.

SANTOS, Milton. A natureza do espaço: técnica e tempo, razão e emoção. 4 ed. 2.reimpr. São Paulo: Editora da Universidade de São Paulo, 2006. Disponível em: $<$ file:///C:/Users/alexandra.rufino/Downloads/A+Natureza+do+Espa\%C3\%A7o++Milton+Santos.pdf>. Acesso em: 20 fev. 2014.

VITORIANO, Isadora Serrano. A ação da rede socioassistencial: quais as possibilidades desta efetivar-se?. Disponível em:

<http://www.joinpp.ufma.br/jornadas/joinpp2011/CdVjornada/JORNADA_EIXO_2011/IMP ASSES_E_DESAFIOS_DAS_POLITICAS_DA_SEGURIDADE_SOCIAL/A_ACAO_DA_ REDE_SOCIOASSISTENCIAL_QUAIS_AS_POSSIBILIDADES_DESTA_EFETIVARSE. pdf>. Acesso em: 12 fev. 2014.

Data de recebimento: 10/04/14

Data de aceite: $28 / 07 / 16$ 


\section{Sobre os autores:}

Alexandra Cronemberger Rufino é Graduada em Direito e mestranda em Políticas Públicas pela Universidade Federal do Piauí (UFPI). Exerce atualmente o cargo de Consultor de Controle Externo no Tribunal de Contas do Estado do Piauí. Endereço eletrônico: alexandrarufino@hotmail.com

Washington Luís de Sousa Bonfim é Doutor em Ciência Política e Sociologia pelo Instituto Universitário de Pesquisa do Rio de Janeiro (IUPERJ). Professor Associado II da Fundação Universidade Federal do Piauí (UFPI), atuando nos Programas de Pós-Graduação em Políticas Públicas e Sociologia. Endereço eletrônico: washbonfim@gmail.com. 